\title{
Pendampingan Perempuan dalam Mendidik Keluarga untuk Menyikapi Informasi Berita Hoax Menjelang Pemilu 2019 di Kabupaten Barito Kuala Kalimantan Selatan
}

\author{
Marhaeni Fajar Kurniawati ${ }^{1}$, Farida Kusuma Wardani ${ }^{2}$ \\ ${ }^{1}$ Magister IImu Komunikasi Universitas Islam Kalimantan Muhammad Arsyad Albanjari, \\ Banjarmasin, Indonesia \\ ${ }^{2}$ Komisi Pemilihan Umum Daerah Kalimantan Selatan, Banjarmasin, Indonesia
}

\begin{abstract}
ABSTRAK
Pentingnya kesadaran masyarakat melalui pemberian suara pada tanggal 17 April 2019, tentunya harus dipahami oleh masyarakat. Sosialisasi perlu dilakukan oleh lembaga terkait seperti KPU, berbagai media massa dan Perguruan Tinggi, agar informasi seputar PEMILU bisa diterima dengan baik oleh masyarakat, terutama masyarakat bisa masyarakat bisa menghindari informasi yang berkaitan dengan berita bohong seputar informasi PEMILU, Sukses PEMILU merupakan sukses bangsa. Untuk mencapai hal tersebut pentingnya pendidikan politik masyarakat melalui sosialisasi pemilu 2019. Seorang ibu menempati posisi yang sangat penting dan strategis dalam sebuah keluarga dalam meningkatkan partisipasi, khususnya pada anak yang baru pertama kali mengikuti Pemilu atau sebagai pemilih pemula.
\end{abstract}

Tujuan dari kegiatan pengabdian masyarakat ini diharapkan menambah pengetahuan dan kesadaran tentang bahaya berita hoax yang dapat mengganggu pelasanaan pemilu bulan April 2019. Pengetahuan masyarakat pemilih tentang tata cara pemilu dan pemberian suara yang disosialisasikan oleh KPUD Kalimanatan Selatan dan Program Studi Magister IImu Komunikasi Universitas Islam Kalimantan Muhammad Arsyad AlBanjari Banjarmasin. Kegiatan ini dapat memberikan manfaat meningkatkan pengetahuan dan kesadaran pentingnya pemilu 2019 sehingga dapat lebih berperan pada pemilu 2019 dan dapat memberikan suara dengan benar, dengan demikian diharapkan terciptanya kondisi yang aman, tertib dan damai. Kegiatan ini sebagai salah satu kegiatan Pengabdian Masyarakat yang dilakukan oleh Magister Ilmu Komunikasi Universitas Islam Kalimantan Muhammad Arsyad AlBanjari Banjarmasin bersama Komisi Pemilihan Umum Daerah Kalimantan Selatan. Metode pelaksaan pendampingan perempuan dalam mendidik keluarga untuk menyikapi informasi berita hoax ini meliputi kegiatan penyuluhan oleh Komisioner Komisi Pemilihan Umum Propinsi Kalimantan Selatan dan dari Magister Ilmu Komunikasi Universitas Islam Kalimantan Muhammad Arsyad AlBanjari Banjarmasin, dilanjutkan dengan simulasi dan tanya jawab. Kegiatan pengabdian masyarakat dilaksanakan pada tanggal 6 September 2018 pukul 13.00 WITA bertempat di masjid Nurul Anwar Barito Kuala Kalimantan Selatan. Hasil akhir yang diharapkan dari adanya kegiatan ini adalah para ibuibu dapat menginformasikan kepada keluarga terdekat dan memberikan edukasi kepada keluarga agar dapat memilah dan memilih informasi sehat terutama yang berkaitan dengan informasi pemilihan umum.

Kata kunci: pendampingan perempuan, mendidik keluarga, informasi 


\begin{abstract}
The importance of public awareness through voting on April 17 2019, of course, must be understood by the public. Socialization needs to be carried out by related institutions such as the KPU, various mass media and universities, so that information about the General Election can be well received by the public, especially the public, so that the public can avoid information related to fake news about election information, PEMILU success is the nation's success. To achieve this, the importance of public political education through the socialization of the 2019 election. A mother occupies a very important and strategic position in a family in increasing participation, especially for children who are participating in elections for the first time or as first-time voters.
\end{abstract}

The purpose of this community service activity is expected to increase knowledge and awareness about the dangers of hoax news that can interfere with the implementation of the April 2019 elections. Knowledge of the voters about election procedures and voting socialized by the South Kalimantan KPUD and the Master of Communication Study Program of the Islamic University of Kalimantan Muhammad Arsyad AlBanjari Banjarmasin. This activity can provide the benefit of increasing knowledge and awareness of the importance of the 2019 election so that it can play a more role in the 2019 elections and be able to vote correctly, thereby creating a safe, orderly and peaceful condition. This activity is one of the Community Service activities carried out by the Master of Communication Science at the Islamic University of Kalimantan Muhammad Arsyad AlBanjari Banjarmasin together with the Regional General Election Commission of South Kalimantan. The method of implementing female assistance in educating families to respond to hoax news information includes counseling activities by the Commissioner of the General Election Commission of South Kalimantan Province and from the Masters of Communication Science at the Islamic University of Kalimantan Muhammad Arsyad AlBanjari Banjarmasin, followed by simulations and questions and answers. Community service activities were carried out on September 62018 at 13.00 WITA at the Nurul Anwar Barito mosque in Kuala Kalimantan, South Kalimantan. The final result expected from this activity is that mothers can inform their immediate family and provide education to families so that they can sort and select healthy information, especially those related to general election information.

Keywords: assistance for women, educating families, information

\title{
PENDAHULUAN
}

Pelaksanaan pemilu dari waktu ke waktu semenjak krisis kepemimpinan dan krisis ekonomi tahun 1998 membutuhkan dukungan dan partisipasi masyarakat, baik pada pemilihan umum anggota legislatif maupun pemilihan presiden. Partisipasi ini penting bagi kualitas demokratisasi politik sebagai representasi obyektif kehendak masyarakat. Maraknya berita negatif yang sengaja dihembuskan oknum dan berita berita bohong atau hoax lainnya menambah ketidak antusias nya masyarakat dengan jalannya pesta demokrasi. Sebanyak 62 konten hoax terkait pemilu 2019 diidentifikasi oleh kementrian Komunikasi dan Informasi (Kementrian Kominfo) selama bulan Agustus sampai dengan bulan Desember 2018. (Kami, 2019).

Berbagai kondisi sosial ekonomi pada akhirnya dalam dekade ini setelah krisis ekonomi masuk pada krisis global yang pada akhirnya akan sampai pada lapisan terbawah yaitu masyarakat. 
Krisis energi mulai dari listrik, BBM, suku bunga perbankan dan sebagainya akan semakin menuntut masyarakat level bawah untuk bekerja lebih keras untuk memenuhi kebutuhannya. Berbagai masalah ekonomi yang terus berlangsung akan memberi peluang masyarakat ekonomi bawah lebih mementingkan pemenuhan kebutuhan ekonomi dibandingkan masalah bangsa, masalah kelangsungan kepemimpinan bangsa melalui pemilu. Hal ini dapat sebagai salah satu pemicu turunnya kesadaran masyarakat pada partisipasi dalam pemilu 2019.

Masih rendahnya kepercayaan masyarakat dan partai politik membuat tingkat partisipasi pemilih dalam pemilihan umum cenderung turun. (Hamid, 2018). Pentingnya kesadaran masyarakat melalui pemberian suara pada tanggal 17 April 2019, tentunya pemberian suara harus dipahami oleh masyarakat. Semakin dekatnya pemilu 2019 membutuhkan adanya suasana pemilu yang kondusif, aman tertib dan damai. Untuk mencapai hal tersebut pentingnya pendidikan politik masyarakat melalui sosialisasi pemilu 2019. Seorang ibu memiliki posisi yang sangat penting dalam meningkatkan partisipasi, khususnya pada anak anak remaja dimana mereka merupakan pengalaman pertama untuk mengikuti kegiatan pemilu, atau pemilih pemula. Berdasarkan data terlihat bahwa pemilih pemula usia 17 than dapat dilihat tabel berikut ini:

Tabel 1. Tipologi Partai Politik

\begin{tabular}{|l|l|l|l|l|}
\hline No. & Kabupaten/Kota & $\mathrm{L}$ & $\mathrm{P}$ & Total \\
\hline 1 & BALANGAN & 4.028 & 3.850 & 7.878 \\
\hline 2 & BANJAR & 16.220 & 15.292 & 31.512 \\
\hline 3 & BANJARBARU & 4.040 & 3.940 & 7.980 \\
\hline 4 & BANJARMASIN & 5.448 & 5.110 & 10.558 \\
\hline 5 & BARITO KUALA & 3.251 & 2.989 & 6.240 \\
\hline 6 & HULU SUNGAI SELATAN & 2.248 & 2.139 & 4.387 \\
\hline 7 & HULU SUNGAI TENGAH & 8.366 & 7.671 & 16.037 \\
\hline 8 & HULU SUNGAI UTARA & 4.064 & 4.005 & 8.069 \\
\hline 9 & KOTABARU & 744 & 676 & 1.420 \\
\hline 10 & TABALONG & 1.855 & 1.759 & 3.614 \\
\hline 11 & TANAH BUMBU & 1.502 & 1.505 & 3.007 \\
\hline 12 & TANAH LAUT & 3.881 & 3.391 & 7.272 \\
\hline 13 & TAPIN & 6.407 & 6.078 & 12.485 \\
\hline & Total & $\mathbf{6 2 . 0 5 4}$ & $\mathbf{5 8 . 4 0 5}$ & $\mathbf{1 2 0 . 4 5 9}$ \\
\hline
\end{tabular}

Sumber: Banjarmasin (2018)

Dilihat dari sebaran tersebut maka jumlah penduduk usia 17 tahun atau usia pemula dalam pemilihan umum cukup besar yaitu 120.459 jiwa, tentunya perlu adanya informasi yang tepat mengenai pemilu. Jika tidak maka akan mendapatkan keterdedahan informasi sesat. Seperti yang dilansir dalam kompasiana.com bahwa kebiasaan anak muda zaman sekarang yang langsung men"share" informasi apa saja yang mereka terima tanpa menelusuri kebenarannya 
terlebih dahulu juga merupakan ancaman tersendiri yang mampu mengguncang pesta demokrasi sehingga jauh dari kata kejujuran dan keadilan. (Dewi, 2019). Dengan demikian diperlukan sosialisasi tentang pemilu melalui orang tua dalam hal ini adalah ibu, alasannya karena ibu adalah sosok yang sangat dekat terhadap keluarga, terutama anak.

Selain waktu sosialisasi yang dilakukan KPU dan berbagai media massa, pentingnya partisipasi elemen masyarakat. Sosialisasi memang belum maksimal, karena itu diharapkan partisipasi dan kerjasama dengan perguruan tinggi untuk penyegaran sosialisasi guna menyukseskan pemilu 2019 karena Sukses PEMILU merupakan sukses bangsa.

\section{Identifikasi dan Perumusan Masalah}

Adanya tingkat penurun pemilih merupakan tantangan yang besar pada KPU terutama di daerah, adanya keterbatasan dalam jarak tempuh antara tempat tinggal dengan tempat pemungutan suara yang jauh merupakan suatu kendala pada masyarakat sehingga masyarakat enggan untuk datang ke TPS yang sudah ditentukan. Penyebab lain adalah karena kondisi kesehatan masyarakat terutama warga yang usia lanjut merupakan kendala dalam Penyebab terjadinya penurunan tingkat pemilih yang paling pokok adalah banyak beredarnya berita-berita hoax yang sering beredar di media terutama di media massa menambah ketidakperdulian pemilih sehingga terjadi penurunan animo masyarakat dalam pemilihan tahun 2019. Peran ibu dalam memberikan edukasi mengenai berita hoax atau berita yang tidak benar, dapat memecah belah persatuan bangsa kepada putra-putri sangat diperlukan sebagai salah satu bentuk kepedulian program studi Magister Ilmu Komunikasi Pasca Sarjana Uniersitas Islam Kalimantan Muhammad Arsyad AlBanjari Banjarmasin melaksanakan sosialisasi kepada ibu-ibu yang tergabung dalam majlis taklim di wilayah Barito Kuala. Kegiatan ini kerjasama Program Studi Management ilmu Komunikasi Universitas Islam Kalimantan dengan KPUD Kalimantan Selatan, kegiatan tersebut ditujukan kepada ibu-ibu majlis taklim, dimaksudkan ibu-ibu sebagai garda terdepan dalam mendidik keluarga bisa memberikan edukasinya kepada putra-putri yang baru mengikuti pemilu tahun 2019 untuk tidak langsung mempercayai berita berita yang bisa memecah persatuan bangsa dan ingin menggagalkan pesta demokrasi di Indonesia.

Berdasarkan uraian tersebut, maka permasalahan yaitu: (1) Bagaimana meningkatkan pengetahuan dan kesadaran masyarakat di Barito Kuala untuk berpartisipasi pada pemilu 2019? (2) Bagaimana peran ibu-ibu di wilayaha Barito Kuala dalam memberikan edukasinya kepada keluarga tentang berita hoax?

Tujuan dari kegiatan Pengabdian masyarakat kepada ibu-ibu majlis taklim di wilayah Barito Kuala Kalimantan Selatan bertujuan untuk: (1) Memberikan pemahaman, pengetahuan dan kesadaran tentang pentingnya pemilu pada pemilu April 2019. Serta menjelaskan bahaya berita hoax bagi generasi muda yang akan menyebabkan perpecahan bangsa. (2) Pengetahuan masyarakat pemilih tentang tata cara pemilu dan pemberian suara yang 
dilakukan KPUD Kalimanatan Selatan dan Program Studi Magister IImu Komunikasi Universitas Islam Kalimantan Muhammad Arsyad AlBanjari Banjarmasin. (3) Secara tidak langsung dapat digunakan sebagai pengenalan Program Studi Magister IImu Komunikasi Universitas Islam Kalimantan Muhammad Arsyad AlBanjari Banjarmasin.

\section{Bentuk dan Manfaat Kegiatan}

Kegiatan ini dapat memberikan manfaat meningkatkan pengetahuan dan kesadaran pentingnya pemilu 2019 sehingga dapat lebih berperan pada pemilu 2019 dan dapat memberikan suara dengan benar dan terciptanya kondisi yang aman, tertib dan damai. Kegiatan ini sebagai salah satu sumber informasi bagi masyarakat tentang tata cara pemilihana umum selain yang disampaikan oleh pemerintah, tokoh masyarakat, partai politik dan media massa. Publikasi yang disampaikan oleh Magister ilmu Komunikasi Universitas Islam Kalimantan Muhammad Arsyad AlBanjari Banjarmasin pada masyarakat melalui komunikasi tatap muka maupun media massa yang meliput.

\section{Khalayak Sasaran}

Sasaran dalam pengabdian ini adalah ibu-ibu yang tergabung dalam pengajian majlis takllim yang berada di wilayah Barito Kuala Kalimantan Tengah, diharapkan nantinya ibu-ibu ini dapat memberikan informasi kepada putra-putri dan juga para tetangganya agar tidak terprovokasi oleh berita berita yang tidak benar, khususnya berita yang berkaitan dengan politik sehingga dengan demikian diharapkan masyarakat dapat mengikuti pemilu pada tanggal 17 April 2019.

\section{METODOLOGI PELAKSANAAN}

Kegiatan pengabdian dilaksanakan dalam bentuk penyuluhan, metode kegiatan yang dilaksanakan berupa presentasi dan tanya jawab.

Presentasi diawali dengan penjelasan tentang peran keluarga dalam pemilihan umum tahun 2019 yang disampaikan oleh ibu Dr. Hatmiati, M.Pd Komisioner Komisi Pemilihan Umum Provinsi Kalimantan Selatan. Selanjutkan disambung dengan penyuluhan tentang peran ibu dalam mendidik keluarga dalam menyikapi informasi berita hoax menjelang Pemilu 2019.

Semua ibu-ibu majlis taklim Nurul Anwar Barito Kuala yang hadir pada acara penyuluhan diberi kesempatan untuk bertanya tentang semua yang belum jelas, tentunya yang berkaitan dengan pemilu, bik yang disampaikan dalam presentasi maupun hal hal lain yang berkaitan dengan masalah teknis pemilihan.

Kegiatan pengabdian masyarakat dilaksanakan pada tanggal 6 September 2018 pukul 13.00 WITA bertempat di masjid Nurul Anwar Barito Kuala Kalimantan. Kegiatan Sosialisasi atau penyuluhan ini dilakukan dalam satu hari dengan materi yang disampaikan sebagai berikut: 


\begin{tabular}{|l|l|}
\hline Waktu & Kegiatan \\
\hline $15.00-15.10$ & Pembukaan \\
\hline $15.10-15.30$ & Pembacaan ayat suci Alqur'an dan terjemahan \\
\hline $15.30-16.00$ & Sambutan sambutan \\
\hline $16.00-17.00$ & Materi: Peran keluarga dalam pemilihan umum tahun 2019 \\
\hline $17.00-18.00$ & $\begin{array}{l}\text { Materi: Peran ibu dalam mendidik keluarga dalam menyikapi } \\
\text { informasi berita hoax menjelang Pemilu 2019 }\end{array}$ \\
\hline $18.00-19.00$ & ISTIRAHAT SHOLAT MAGRIB \\
\hline $19.00-20.00$ & Tanya Jawab \\
\hline 20.00 & Penutup \\
\hline
\end{tabular}

\section{HASIL DAN PEMBAHASAN}

\section{Hasil Kegiatan}

Pelaksanaan sosialisasi dilaksanakan 1 (satu) kali bertempat di masjid Nurul Anwar terletak di wilayah Barito Kuala merupakan kerjasama KPUD Kalimantan Selatan dengan DKM Masjid Nurul Anwar dan Program Studi Magister IImu Komunikasi Universitas Islam Kalimantan Muhammad Arsyad AlBanjari Banjarmasin, dilaksanakan pada hari Kamis, 6 September 2018 di mulai pada pukul 15.00 WITA sampai dengan selesai.

Gambar 1. Bersama ibu-ibu majilis taklim Nurul Anwar Barito Kuala Kalimatan Selatan

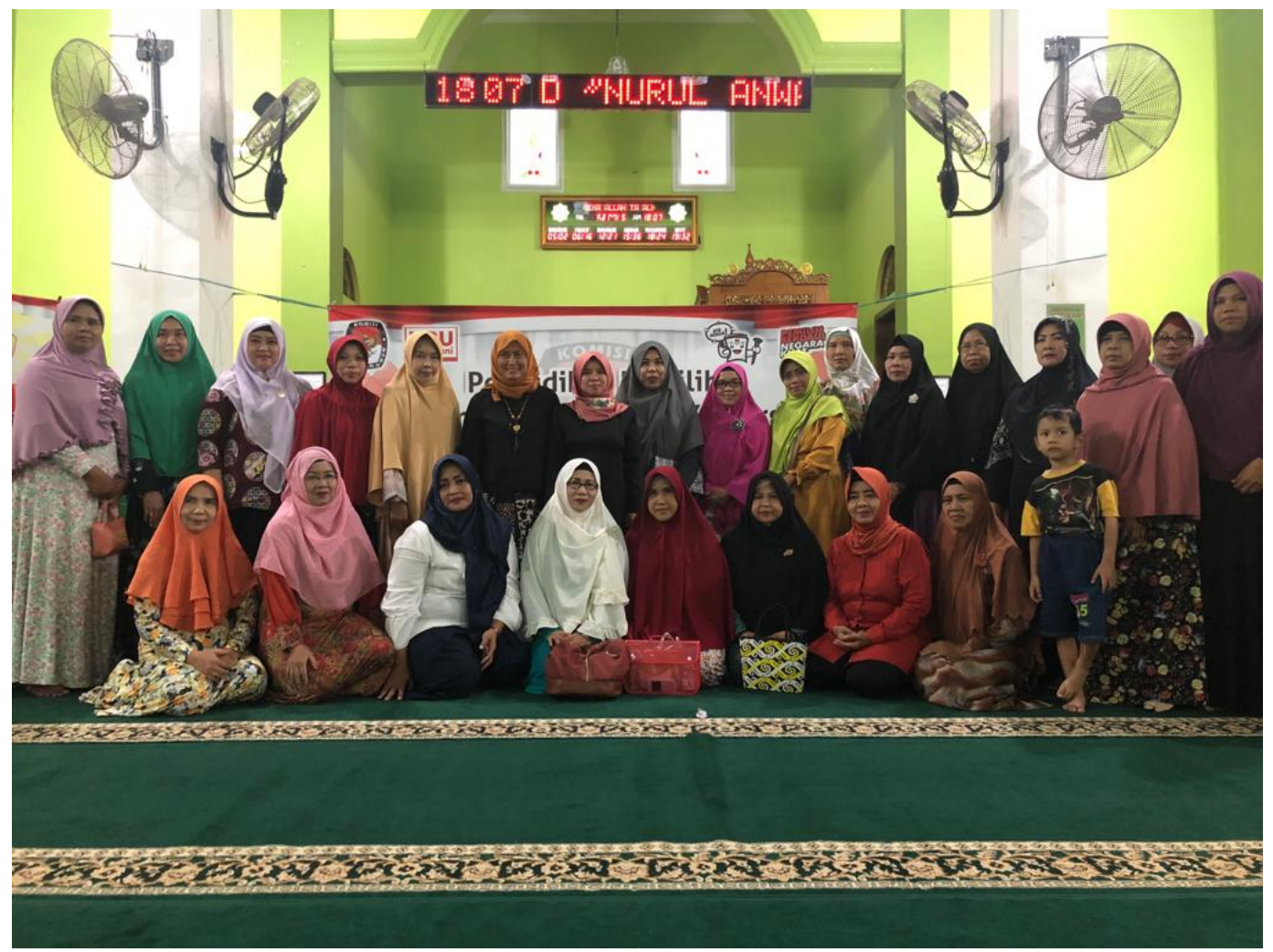


Sasaran dalam sosialisasi ini adalah ibu-ibu yang tergabung dalam majils taklim Nurul Anwar Barito Kuala, karena diharapkan para ibu-ibu bisa memberikan pendidikan dan informasi yang bermanfaat kepada putra-putri pemilih pemula untuk menyikapi informasi berita hoax yang dapat mengganggu kesuksesan keberlangsungan pemilu 2019. Tema sosialisasi merujuk pada tema KPU tentang PEMILU 2019. Adapun materi yang disampaikan antara lain: (1) Penyelengaraan Pemilu di Indonesia; (2) Proses Penyelengaraan Pemilu di Indonesia; (3) Partisipasi Pemilih Muda dalam Pemilihan Umum; (4) Peran ibu-ibu dalam pendidikan pemilih kepada keluarga terutama kepada pemilih pemula; (5) Menjadi pemilih yang baik; (6) Menjalin komunikasi yang efektif antara ibu dengan anak terutama yang berkaitan dengan menangkis berita dan informasi yang tidak benar seputar pemilu.

Kegiatan ini diharapkan dapat menghasilkan fasilitator kepemiluan dan menangkis berita hoax yang beredar di masyarakat bagi keluarga terutama remaja usia pemilih pemula yaitu usia 17 tahun ke atas.

Narasumber pada sosialisasi adalah Dr. Hatmiati, M.Pd Komisioner Komisi Pemilihan Umum Provinsi Kalimantan Selatan, memberikan materi dengan judul "Peran keluarga dalam Pemilihan Umum tahun 2019". Pemateri kedua Dr. Marhaeni Fajar Kurniawati, M.Si Katua Program Studi Magister Ilmu Komunikasi Universitas Islam Kalimantan Muhammad Arsyad AlBanjari Banjarmasin, memberi tema tentang "Peran Ibu dalam Mendidik Keluarga untuk Menyikapi Informasi Berita Hoax Menjelang PEMILU 2019".

Gambar 2. Suasana Sosialisasi di majlis taklim Nurul Anwar Barito Kuala Kalimantan Selatan

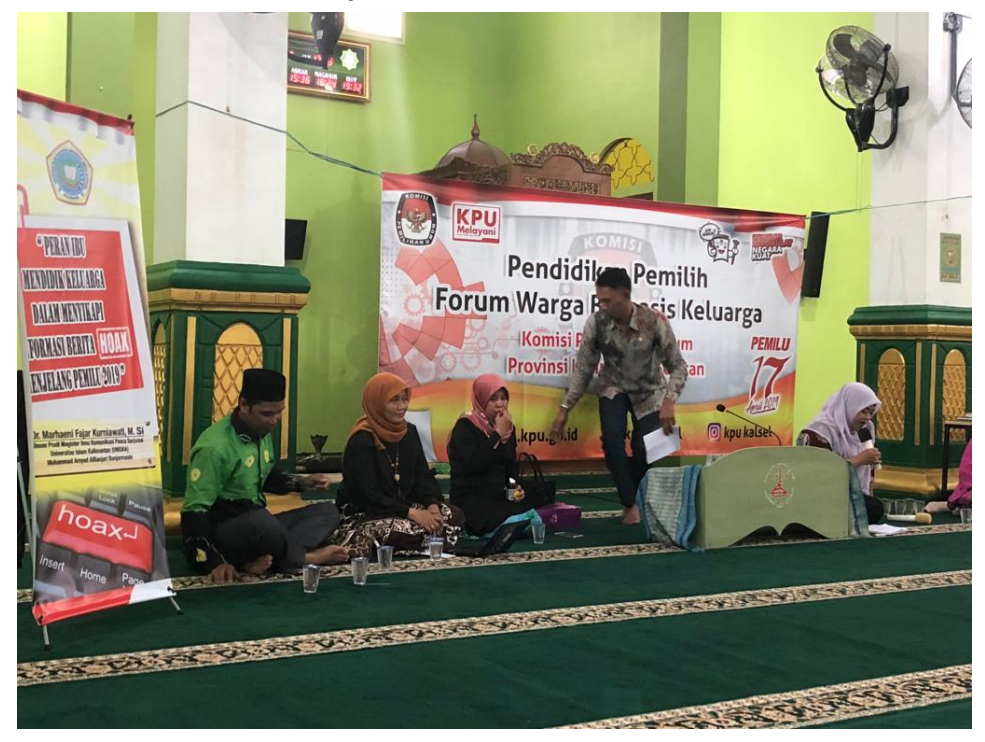

Semua peserta yang ikut sosialisasi sangat tertarik dengan kegiatan sosialisasi, ini dapat dilihat dari banyaknya pertanyaan yang disampikan ibu-ibu pada acara tersebut. Hasil Tanya jawab menunjukkan bahwa semua tertarik dengan pemilu yang akan diselenggarakan pada bulan April 2019, beberapa pertanyaan yang dikemukakan antara lain menyangkut masalah: (1) tata 
cara pemberian suara; (2) mengantisipasi pemilih yang sudah lanjut usia; (3) mengantisipasi pemilih yang sakit dan tidak bisa keluar rumah karena sakitnya; (4) syarat-syarat surat suara sah; (5) pentingnya partisipasi masyarakat dalam pemilu bagi demokrasi dan kelangsungan bangsa Indonesia; (6) suasana tertib aman dan kampanye damai; (7) menyikapi berita hoax terutama di media social; (8) hal-hal yang perlu dipersiapkan H-1 pelaksanaan pemilu 2019.

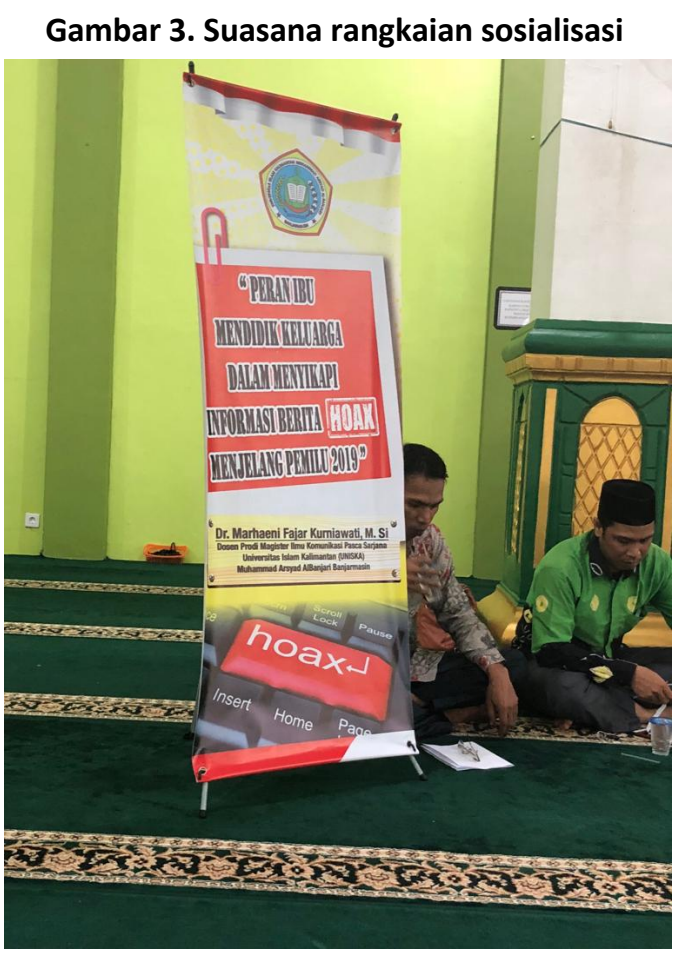

\section{Evaluasi Kegiatan}

Berdasarkan perencanaan sosialisasi, evaluasi dilakukan dengan cara: (1) target peserta dan sasaran peserta sudah sesuai dengan perencanaan sosialisasi; (2) seluruh rangkaian acara dapat dilaksanakan; (3) terlihatnya antusiasmen dan partisipasi masyarakat pada acara tersebut; (4) sosialisasi tentang Peran keluarga dalam Pemilihan Umum tahun 2019 dan Peran ibu dalam mendidik keluarga dalam menyikapi informasi berita hoax menjelang PEMILU 2019 dapat disampaikan; (5) sasaran yaitu ibu-ibu majlis taklim Nurul Anwar Barito Kuala terlihat interaktif dalam rangkaian semua acara hingga selesai.

Rangkaian acara dimulai pemateri disertai dengan peragaan tentang tata cara pemberian suara dan sebagainya. Narasumber pada sosialisasi adalah Dr. Hatmiati, M.Pd Komisioner Komisi Pemilihan Umum Provinsi Kalimantan Selatan, memberikan materi dengan judul “Peran keluarga dalam Pemilihan Umum tahun 2019". Pemateri kedua Dr. Marhaeni Fajar Kurniawati, M.Si Katua Program Studi Magister Ilmu Komunikasi Universitas Islam Kalimantan Muhammad Arsyad AlBanjari Banjarmasin, memberi tema tentang "Peran Ibu dalam Mendidik Keluarga untuk Menyikapi Informasi Berita Hoax Menjelang PEMILU 2019". 
Dukungan dari KPUD Kalimantan Selatan, PPS, DKM Majid Nurul Anwar nampak dalam sosialisasi ini, hal ini diduga karena kepedulian semuanya pada terselenggaranya pemilu yang lancar, tertib dan aman. Disamping itu maraknya berita bohong yang dikhawatirkan akan mengganggu kelancaran pemilu bisa dicegah.

Pada sosialisasi antusiasme ibu ibu sangat baik, ini dapat terlihat dari banyaknya pertanyaan yang ditanyakan langsung pada KPUD dan dari MIKom UNISKA. Partisipasi ibu-ibu dapat diketahui dari peserta tidak beranjak meninggalkan tempat hingga acara selesai.

\section{Faktor Pendukung Kegiatan}

Ada beberapa faktor pendukung pada saat berlangsungnya kegiatan penyuluhan. Pertama, Ibu-ibu memiliki keinginan yang kuat untuk mengetahui informasi yang tidak benar menyangkut pemalksaan pemilu. Kedua, adanya semangat untuk menjaga keutuhan NKRI, hal ini dapat dilihat dari antusiasnya para peserta dalam mengikuti kegiatan ini dan banyaknya pertanyaan- pertanyaan dalam sesi tanya jawab dan sesi diskusi dengan peserta. Ketiga, kegiatan sosialisasi ini medapat sambutan baik dari masyarakat dan aparat setempat.

\section{Faktor Penghambat Kegiatan}

Berhubung jarak yang ditempuh sangat jauh, dan kendala tidak ada transportasi umum, tempat yang agak sulit dijangkau maka kegaiatan tidak tepat waktu dari awal pelaksanaan yang telah ditentukan panitia.

Ibu-ibu menyatakan senang pada kegiatan pengabdian masyarakat yang diselenggarakan oleh Magister IImu Komunikasi Universitas Islam Kalimantan Muhammad Arsyad AlBanjari Banjarmasin Kalimantan Selatan bekerjasama dengan Komisi Pemilihan Umum Daerah Kalimantan Selatan.

Ibu-ibu mendapat pengetahuan dan pemahaman tentang bagaimana cara berkomunikasi dengan baik kepada keluarga, terutama pada anak anak menjelang dewasa, hambatan dan kendala yang seringkali dihadapi serta solusinya agar komunikasi yang terjalin di dalam keluarga dapat lebih baik lagi, terutama yang berkaitan dengan menangkalan berita dan informasi yang tidak benar atau hoax seputar Pemilu.

\section{SIMPULAN}

Pengetahuan ibu-ibu tentang peran pentingnya di keluarga diharapakan dapat membantu pemerintah untuk mensukseskan pemilu 2019, salah satu cara yang diharapakan adalah 
memberikan pendidikan kepada keluarga dan tetangga sekitarnya akan bahaya berita bohong atau hoax yang sengaja disebar-sebar untuk mengganggu jalannya pemilu 2019.

Tata cara sosialisasi pemilu secara interaktif antara pemateri dengan ibu-ibu dan tanya jawab lebih mudah dimengerti.

Berdasarkan pengamatan, pengetahuan yang paling diingat oleh ibu-ibu adalah tanggal pelaksanaan pemilu, tata cara pemberian suara dan bagaimana menangkis serangan hoax.

\section{DAFTAR PUSTAKA}

Dewi, D.L. (2019, Oktober 25). Perkembangan Kids Zaman Now. Kompasiana. https://www.kompasiana.com/denta37481/5db29d39097f3611846bf496/perkemba ngan-kids-zaman-now

Hamid, H. (2018, September 1). Partisipasi Pemilih Terus Menurun. Kompas. https://kompas.id/baca/polhuk/2018/09/01/partisipasi-pemilih-terus-menurun-2/

Hartley, P. (1999). Interpersonal Communication (2nd ed.). Routledge.

Ihroni, T.O. (Ed.). (1999). Bunga Rampai: Sosiologi Keluarga. Yayasan Obor Indonesia.

Kami, I.M., (2019, Januari 2). 62 Hoax Pemilu 2019 Teridentifikasi Kominfo, Ini Daftarnya. Detikcom. https://news.detik.com/berita/d-4368351/62-hoax-pemilu-2019teridentifikasi-kominfo-ini-daftarnya

Khairuddin, H. (2002). Sosiologi Keluarga. Liberty.

Suhendi, H., \& Wahyu, R. (2001). Pengantar Studi Sosilogi Keluarga. Pustaka Setia.

Soekanto, S. (2002). Sosiologi keluarga : tentang ikhwal keluarga, remaja dan anak. Rineka Cipta.

Soekanto, S. (2002). Sosiologi: suatu pengantar (4th ed.). Raja Grafindo Persada. 